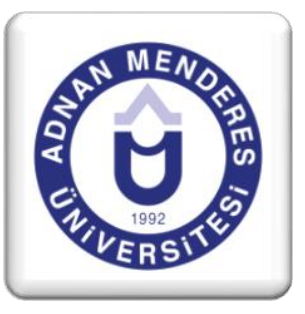

\section{Rasyo Analizleri İle Finansal Performansın Ölçülmesi: Borsa İstanbul'da Faaliyet Gösteren Havayolu Şirketleri'nde Bir Uygulama}

Umut Tolga GÜMÜŞ ${ }^{1}$,Neslihan BOLEL ${ }^{2}$



\title{
ÖZET
}

Son yıllarda teknoloji ve iş dünyasında yaşanan gelişmeler havayolu sektöründe de değişimlere neden olmuştur. Yaşanan bu gelişmeler, gerek yurt içine gerekse yurt dışına olan yolculuklarda havayollarına olan talebi arttırmıştır. Artan bu talep hem havayolu taşımacılı̆̆ı yapan firma sayısını arttırmış olmakla birlikte; hem de bu firmaların finansal yapılarında değişikliğe yol açmıştır. Bu çalışmada da; havayolu şirketlerinin tablolarındaki finansal değişiklikler ele alınacaktır. Borsa İstanbul'da faaliyet gösteren Türk Hava Yolları A.Ş. ile Pegasus Hava Yolları A.Ş’nin 2010-2015 yılları arası mali tablo değerleri ele alınarak Rasyo Tekniği formülleriyle şirketlerin finansal performansı analiz edilmiş̧ir. Çıkan sonuçlara göre her iki şirket hakkında ayrı ayrı yorumlarda bulunulmuştur.

Anahtar Kelimeler: Finansal Performans, Rasyo Analizi, Türk Hava Yolları, Pegasus Hava Yolları

\section{Measuring The Financial Performance and Ratio Analysis: An Application in Airway Companies Operating in The Istanbul Stock Exchange}

\begin{abstract}
Developments in technology and the business world in recent years has led to changes in the airline industry. These developments are, the journey to the need for a domestic as well as foreign airlines has increased the demand for. This increasing demand has not only increased the number of companies engaged in air transport but also has led to changes in the financial structure of these companies .In this study, changes in airline companies' financial statements will be discussed. Financial performance of companies has been analyzed by considering the financial statement values between 2010-2015 years of Turkish Airlines and Pegasus Airlines carrying on a business in Istanbul Stock Exchange with the help of formullas of Rasyo Technique .According to the results , Separate comments have been made for both companies.
\end{abstract}

Key words: Financial performance, Rasyo analysis, Türkish Airlines , Pegasus Airlines

\footnotetext{
${ }^{1}$ Yrd.Doç.Dr., Adnan Menderes Üniversitesi, Nazilli İ.İ.B.F., Nazilli, Aydın.

${ }^{2}$ Yüksek Lisans Öğrencisi, Adnan Menderes Üniversitesi.
} 


\section{I.GIRISS}

Ülkelerin ekonomik ve sosyal olarak kalkınmalarında havayolu taşımacıllı̆ı önemli bir paya sahiptir. Türkiye'de havayolu taşımacılığı yapan firmaların finansal yapıları incelendiği zaman bu firmaların dış faktörlerden oldukça etkilendiği görülür. Havayolu firmalarının mali tablolarını çok değişik yollarla analiz edilip yorumlar yapılıp bu firmalar hakkında çıkarımlarda bulunulabilir. Havayolu firmaların performans sonuçlarını çeşitli analizlerle görebildiğimiz gibi bir diğer yöntem de Finansal Performans Analizi'dir.

Finansal performans analizi, bir işletmenin muhasebe ve finansal tablolarından faydalanılarak faaliyet ve finansal yapı özelliklerinin belirlenmesi işlemidir. $\mathrm{Bu}$ analizin amacı, işletmenin finansal kayıt ve raporlarından işletme yönetiminin verimliliğinin ve performansının belirlenmesidir ( Bhunia vd., 2011: 269). Finansal performans işletmelerin finansal pozisyonunu, yatırımlarının güvenliğinin ve riskinin değerlendirilmesi sürecidir. Finansal performans ölçümleri geçmişi değerlendirme, gelecek için yatırım ve finansman kararları alma, kaynak kullanımı ve yöneticilerin performanslarının değerlendirilmesinde kullanilmaktadır.

Finansal analiz firmaların mali tablolarının analiz edilerek çeşitli sonuçlar çıkarılması ve elde edilen sonuçlar yorumlanarak firmayla ilgili çıkarımlarda bulunma sürecidir. Yöneticiler finansal analiz yaparak firmanın finansal durumunu takip edebilirler. Finansal analiz sonuçlarının firmanın finansal kararlarında mutlaka kullanılması gerekir. Finansal tabloların analizinde birçok teknik bulunmaktadır. Bu teknikler içerisinde en çok kullanılan hem popülaritesi hem de işlevselliği en yüksek olan teknik oran(rasyo) analizidir. Ayrıca, bir firmada finans yönetiminin temel amacı firmanın piyasa değerinin en yüksek seviyeye çıkarmaktır. Firma performansının ölçülmesinde ve firma değerini etkileyen en temel unsurlardan birisi de kar payı dağıtım politikasıdır. Yapılan mali analizler ile elde edilen bulgular kar payı dağıtım politikasının belirlenmesinde büyük rol oynar (Beyazıtlı, Kaderli, Gürel, 2008:2)

Kâr payı dağıtma, ya da dağıtmama kararının şirketin piyasa değeri üzerinde doğrudan bir etkisinin bulunduğu finansman yazınında genel olarak kabul edilmektedir. Bir şirketin piyasa değeri hisse senedi adedi ile hisse senedi fiyatının çarpımı sonucunda elde ediliyorsa bu denklemde kâr payı dağıtım kararının hisse senedi fiyatı üzerindeki etkisinin ortaya konması gerekmektedir. Kâr payı verimi kavramı temel olarak bu ilişkiyi açıklamaya dönük bir oran olarak kullanılmaktadır. Belli bir dönem aralığında hisse başına düşen nakit kâr payı ile hissenin elde ediliş maliyeti arasındaki ilişkiye kâr payı verimi denir (Gürel E., 2011:31).

$\mathrm{Bu}$ çalışmada ilk olarak finansal performans ölçümünde kullanılan rasyo analizi hakkında bilgi verilecek devamında Borsa İstanbul'da faaliyet gösteren hava yolu şirketleri kısaca anlatılıp, bu şirketlerin beş yıllık finansal tablo kalemlerinden yararlanılarak şirketlere rasyo tekniği uygulanacaktır. Çalışmanın son kısmında ise elde edilen sonuçlar yorumlanarak şirketlerin finansal performansları analiz edilecektir.

\section{LITERATÜR TARAMASI}

Yeşilay (2014), çalışmasında Borsa İstanbul'da işlem gören beyaz eşya firmalarının finansal performanslarını değerlendirdikleri çalışmasında oran tekniğini kullanmıştır.

Meydan ve diğerleri (2016), çalışmalarında Borsa İstanbul'da işlem gören gıda firmalarının finansal performansları Gri İlişkisel Analiz Yöntemi ile değerlendirilmiştir ve firmalar hakkında yorumlar yapılmıştır.

Öncü, Çömlekçi ve Coşkun(2013), çalışmalarında Havayolu işletmelerinin performanslarının ölçülmesinde Veri Zayıflama Analizinden(VZA) hareketle havayolu şirketlerinin finansal performanslarını analiz etmişlerdir. 
Uygurtürk ve Korkmaz çalışmalarında(2012) Borsa İstanbul'da faaliyet gösteren ana metal sanayi endeksi kapsamında yer alan 13 işletmeye ait 2006-2010 dönemleri arası mali tabloları kullanılarak işletmelerin finansal performansları TOPSİS yöntemi ile analiz edilmiştir.

Kaderli (2006) y1lı İMKB'de İşlem Gören Gıda Sektörü Şirketlerinin Finansal Performansının Ölçülmesi ve Özsermaye Karlılığını Etkileyen Faktörlerinin Belirlenmesi adlı çalışmasında gıda şirketlerinin karlılığını ortaya çıkarmıştır.

Karatay, Şahin, Yalçın, Kırtıloğlu'nun Sivil Havacılık Sektörünün Ulusal ve Uluslararası Düzeyde İncelenmesi adlı çalışmalarında sivil havacılık faaliyetlerini ele almışlardır.

Ömürbek ve Kınay(2013) yılı Havayolu Taşımacılı̆̆ 1 Sektöründe Topsis Yöntemi ile Finansal Performans Değerlendirilmesi çalışmasından havayolu taşımacılık firmalarını değerlendirmişlerdir.

Ecer, Günay(2014) Borsa İstanbul'da İşlem Gören Turizm Şirketlerinin Finansal Performanslarını Gri İlişkisel Analiz Yöntemi ile ölçmeye çalışmışlardır.

\section{ORAN (RASYO) ANALİí}

Oran analizi bilanço ve gelir tablosundaki kalemlerin birbirleriyle oranlanması ve elde edilen bulgulardan sonuçlar çıkarılması sürecidir. Oran analizinde bütün kalemler birbiriyle oranlanmaz, birbirleriyle oranlandığında anlam teşkil edecek kalemler birbiriyle oranlanır. Oran analizi yaparken dört grup oran hesaplanır. Bu oran grupları şunlardır:

* Likidite Oranları

* Kaldıraç(Mali Yapı)Oranları

* Faaliyet Oranları

* Karlilık Oranlar1

\section{A)LIKIIDITE ORANLARI}

Likidite oranları bir firmanın borç ödeme gücünü, işletme sermayesinin yeterli olup olmadığını ve nakit sıkıntısı problemiyle karşı karşıya kalma ihtimalinin olup olmadığı konusunda çok kuvvetli bilgiler verirler (Akgüç Ö. 1994:21). Belki de bu oranlar içerisinde en önemli olanı cari orandır(Samuels, Brayshaw2000:55). Bu anlamda en önemli grubun bu olduğu söylenir. Likidite oranları ile başlıca bakılması gereken oranlar şunlardır:

1) Cari Oran: Dönen Varlıklar / Kısa Vadeli Borçlar

2)Asit Test Oranı (Likidite Oranı): (Dönen Varlıklar - Stoklar) / Kısa Vadeli Borçlar

3) Hazır Değerler Oranı (Nakit Oranı): Hazır Değerler/Kısa Vadeli Yabancı Kaynaklar

4)Karşılama Oranı: Ticari Alacaklar/Ticari Borçlar

\section{B) KALDIRAÇ(MALİ YAPI) ORANLARI}

İşletmenin mali yapısının sağlıklı olup olmadığını ölçmede kullanılan oranlardır. İşletmenin öz kaynaklarının yeterli olup olmadığını kaynak yapısı içinde borç ve öz kaynakların dengeli olup olmadığını öz kaynakların hangi kalemlerine aktarıldığını göstermeye yarayan oranlardır. Bu grupta yer alan başlıca oranlar şunlardır:

1)Finansal Kaldıraç Oranı: Yabancı Kaynaklar/Aktif(Pasif)Toplamı

2)Finansman Oranı: Yabancı Kaynaklar/Öz Kaynaklar

3)Maddi Duran Varlıkların Öz kaynaklara Oranı: Maddi Duran Varlıklar/Öz Kaynaklar 4)Öz Kaynakların Aktif Toplama Oranı: Öz Kaynaklar/Aktif Toplamı

5)Kısa Vadeli Yabancı Kaynakların Toplam Kaynaklara Oranı: Kisa Vadeli Yabancı Kaynaklar/Aktif (Pasif) Toplamı 
6)Uzun Vadeli Yabancı Kaynakların Toplam Kaynaklara Oranı: Uzun Vadeli Yabancı Kaynaklar/Aktif (Pasif) Toplamı

\section{C) FAALIYET (ETKINLIIK) ORANLARI}

Bu grup oranlar işletme faaliyetlerinin ne ölçüde etkin ve verimli bir biçimde yürütüldügünü ortaya koymak için hesaplanır. Bu grup oranları yorumlarken mutlaka sektör ortalamalarına bakılmalıdır. Faaliyet oranları genellikle rakip işletmelerle karşılaştırma yapmak için kullanılır.

1)Alacak Devir Hızı (Dönüşüm Çabukluğu): Net Satışlar/Ticari Alacaklar

2)Ortalama Tahsil Süresi:365/Alacak Devir Hızı

3)Borçların Devir Hızı:Net Satışlar/Ticari Borçlar

4)Ortalama Borç Ödeme Süresi:365/Borçların Devir Hızı

5)Stok Devir Hızı: Satılan Malın Maliyeti/Ortalama Stoklar

6)Dönen Varlık Devir Hızı: Net Satışlar/Dönen Varlıklar

\section{D) KARLILIK ORANLARI}

$\mathrm{Bu}$ grup oranlar işletmenin satışlarından ne oranda kar ettiğini ortakların koymuş olduğu sermayenin ne kadar etkin ve verimli kullanılıp kullanılmadığını işletme yöneticilerinin yönetim ve performansının ne kadar iyi olup olmadığını ortaya koymaya yarayan oranlardır.

1)Net Karın Öz Kaynaklara Oranı: Net Kar/Öz Kaynaklar

2)Net Karın Aktif Toplama Oranı: Net Kar/Aktif Toplamı

3)Brüt Satış Karının Net Satışlara Oranı: Brüt Satış Karı/Net Satışlar

\section{HAVA YOLU TAŞIMACILIĞI SEKTÖRÜ}

Türkiye'de sivil havacılık faaliyetleri 1912 yılında başlamıştır ve 1956 yılında Devlet Hava Meydanları'nın kurulması ile sivil havacılık faaliyetleri hız kazanmıştır. 1983 tarihinde Sivil Havacılık Kanunu yürürlüğe girmiştir. 1990 yılından sonra sektöre yeni firmaların katılması ile birlikte sektörde rekabet artmıştır. Artan havayoluna karşı havayolunu tercih eden müşteri sayısında da artış yaşanmıştır.

Sivil Havacılık Genel Müdürlügü Raporlarına 2015 yılında havacılık sektöründe Koltuk Kapasitesi 83.386 olmuştur. Tarifeli Seferlerde kullanılan Uçak Sayısı 458'e ulaşmıştır. Uçak trafiği; iç hat 388 bin, dış hat 271 bin ve transit 171 bin olmak üzere toplam 831 bini aşmıştır.

\section{A)Türk Hava Yolları Anonim Ortaklığı}

Türkiye'nin "yükselen değeri” Türk Hava Yolları, 82 yıl önce 5 uçakla başladığı yolculuğuna bugün, 298 (yolcu ve kargo) uçaktan oluşan filosu ve ilk günkü heyecanı ile devam ediyor. Kaydettiği büyüme rakamları ile dünyanın önde gelen havayolu şirketleri arasında anılan Türk Hava Yolları, 2013'de aldığı önemli kararla Türk Sivil Havacılık tarihinin en büyük uçak alımına imza attı. Bayrak taşıyıcı havayolu bu adımla, önümüzdeki birkaç yıl içerisinde filo yaş ortalamasını da düşürmek suretiyle hizmet kalitesinde çizdiği yükselen grafiği daha da yukarılara çekmeyi hedeflemekte. Filosuna katılmaya başlayan 212 adet dar gövde uçak ve kira süresi sona erecek uçaklar göz önüne alındığında, 2020 yılı sonunda Türk Hava Yolları filosunda kargo uçakları dâhil, toplam uçak sayısının 421'i bulması bekleniyor. Halen yaklaşık ortalaması 6,9 olan filo yaşının ise, yeni uçakların filloya katılımıyla 6'nın altına düşmesi öngörülüyor. 


\section{B)Pegasus Hava Yolları}

Pegasus havacılık sektörüne ilk adımını 1990 yılında Aer Lingus, Silkar Yatırım ve Net Holding'in ortak girişimiyle İstanbul'da kurulan Pegasus, charter uçuşlarla katılmıştır. 2005 yılında Şevket Sabancı ve ailesine ait olan Esas Holding A.Ş. tarafından satın alınmış ve aynı yıl Kasım ayında tarifeli iç hat seferlerine başlayarak Türkiye'de faaliyet gösteren 4. tarifeli havayolu olmuştur. Pegasus Hava Yolları 2014 yılı toplam hasılatı 2013 yılına göre yüzde 28.7 artışla 3.08 milyar liraya, net kârı ise yüzde 56.3 artarak 143.3 milyon liraya yükselmiştir(Vikipedia 2014).

\section{V.RASYO ANALIZİ UYGULAMA SONUCCLARI}

Çalışmanın bu bölümünde, Borsa İstanbul'da işlem gören hava yolu firmalarından Türk Hava Yolları A.Ş. ile Pegasus Hava Yolları'nın mali tabloları rasyo analizi ile analiz edilerek yorumlalar yapilacaktır.

Tablo:1 Türk Hava Yolları A.S. Rasyo Sonuçarı

\begin{tabular}{|c|c|c|c|c|c|}
\hline \multicolumn{6}{|l|}{ LİKİİTE ORANLARI } \\
\hline YILLAR & 2010 & 2011 & 2012 & 2013 & 2014 \\
\hline Cari oran & 1.37 & 1.03 & 0.58 & 1.0055 & 0.77 \\
\hline Asit test oran 1 & 1.3 & 0.97 & 0.53 & 0.95 & 0.72 \\
\hline Nakit oran1 & 0.35 & 0.45 & 0.27 & 0.31 & 0.2 \\
\hline Karşılama oranı & 0.78 & 0.76 & 0.85 & 0.79 & 0.69 \\
\hline \multicolumn{6}{|l|}{ FAALIYET ORANLARI } \\
\hline Alacak devir hızı & 14.58 & 15.54 & 19.08 & 16.35 & 22.85 \\
\hline Ort.tah.süresi & 25.03 & 23.48 & 19.13 & 22.32 & 15.97 \\
\hline Borçların devir hızı & 11.44 & 11.8 & 16.24 & 12.94 & 15.7 \\
\hline Ort.ödeme süresi & 31 & 30 & 22 & 28 & 23 \\
\hline Dönen varlık devir hızı & 2.41 & 2.9 & 3.82 & 4.14 & 3.68 \\
\hline Stok devir hızı & 38,65 & 38,87 & 45,20 & 44,70 & 43,81 \\
\hline Ort.stokta kalma süresi & 9,44 & 9,39 & 8,07 & 8,16 & 8,33 \\
\hline \multicolumn{6}{|l|}{ MALİ YAPI ORANLARI } \\
\hline Kaldıraç oranı & 0.65 & 0.73 & 0.71 & 0.87 & 0.89 \\
\hline Finansman oran 1 & 1.84 & 2.64 & 2.47 & 2.65 & 2.48 \\
\hline Mad.du.var/öz kaynak oranı & 1.72 & 2.47 & 2.43 & 2.46 & 2.33 \\
\hline Öz kaynak/aktif oranı & 0.35 & 0.27 & 0.28 & 0.27 & 0.28 \\
\hline Kvyk/top.kaynak & 0.24 & 0.24 & 0.24 & 0.26 & 0.27 \\
\hline Uvyk/top.kaynak & 0.41 & 0.48 & 0.47 & 0.46 & 0.45 \\
\hline \multicolumn{6}{|l|}{ KARLILIK ORANLARI } \\
\hline Net kar/öz kaynak & 0.07 & 0.004 & 0.21 & 0.09 & 0.19 \\
\hline Net kar/aktif toplamı & 0.02 & 0.01 & 0.06 & 0.03 & 0.05 \\
\hline Brüt satış karı/net satışlar & 0.09 & 0.24 & 0.2 & 0.18 & 0.17 \\
\hline
\end{tabular}

Tablo 1'de görüldüğü üzere, Türk Hava Yolları A.Ş'nin likidite oranlarına göre borç ödeme gücünün yerinde olduğunu ve işletmenin nakit sıkıntısı ile karşılaşmayacağını söyleyebiliriz. İşletme bazı yıllarda oranları düşük çıksa da bu durumu son yıllarda toparlamıştır. İyi bir finans yönetiminin şirkette olduğu bu sonuçlara bakılarak söylenilebilir. 
Faaliyet oranlarını ele alırsak işletmenin faaliyetlerini etkin bir şekilde yürüttüğünü söyleyebiliriz. İşletme alacaklarını zamanında tahsil ediyor ve borç ödeme süresi alacak ödemeden fazla olduğu için borçlarını ödemede herhangi bir zorlukla karşılaşmayacak diyebiliriz. Ayrıca işletmenin stok devir oranı oldukça iyidir buda işletmenin fon yaratma gücüne sahip olduğunu göstermektedir.

Mali yap1 oranları incelendiği zaman firmanın borçluluk düzeyinin fazla olduğu göze çarpmaktadır. Firmaya yatırım yapanların değil alınan borçlarla firmanın faaliyetlerini yürüttüğünü söyleyebiliriz.

Karlılık oranlarına bakacak olursak, firmanın karlılık oranlarının iyi olduğunu söyleyebiliriz. Aynı sektörde faaliyet gösterdiği diğer firmanınkinden bazı oranları düşük olabilir fakat genel itibari ile iyidir diyebiliriz.

Tablo:2 Pegasus Hava Yolları Rasyo Sonuçları

\begin{tabular}{|l|l|l|l|l|l|}
\hline LIKİDİTE ORANLARI & & & & & \\
\hline YILLAR & 2010 & 2011 & 2012 & 2013 & 2014 \\
\hline Cari oran & 0.28 & 0.35 & 0.63 & 1.75 & 1.75 \\
\hline Asit test oranı & 0.27 & 0.35 & 0.63 & 1.75 & 1.74 \\
\hline Nakit oranı & 0.13 & 0.056 & 0.42 & 1.29 & 0.99 \\
\hline Karşılama oranı & 0.34 & 0.78 & 0.47 & 1.14 & 1.19 \\
\hline MALİ YAPI ORANLARI & & & & & \\
\hline Kaldıraç oranı & 0.86 & 0.9 & 0.85 & 0.67 & 0.67 \\
\hline Finansman oranları & 6.3 & 8.7 & 5.7 & 2.05 & 2.04 \\
\hline Mad.du.var/öz kaynak & 5.05 & 7.48 & 5.28 & 0.6 & 1.66 \\
\hline Öz kaynak/aktif toplamı & 0.14 & 0.1 & 0.14 & 0.32 & 0.33 \\
\hline Kvyk/toplam kaynak & 0.31 & 0.3 & 0.02 & 0.19 & 0.24 \\
\hline Uvyk/toplam kaynak & 0.55 & 0.59 & 0.6 & 0.48 & 0.42 \\
\hline FAALIYET ETKINLİK ORANLARI & & & & & \\
\hline Alacak devir hızı & 52.82 & 18.86 & 12.52 & 45.85 & 13.21 \\
\hline Ort.tah süresi & 6.91 & 19.35 & 7.97 & 29.15 & 27.63 \\
\hline Borçların devir hızı & 17.98 & 14.74 & 21.68 & 12.18 & 18.42 \\
\hline Ort.ödeme süresi & 20.30 & 24.76 & 16.83 & 30 & 19.81 \\
\hline Dönen varlık devir hızı & 8.97 & 7.49 & 5.65 & 1.95 & 2.04 \\
\hline KARLILIK ORANLARI & & & & & \\
\hline Net kar/özkaynak & 0.13 & 0.1 & 0.42 & 0.07 & 0.12 \\
\hline Net kar/aktif toplamı & 0.017 & 0.01 & 0.06 & 0.02 & 0.04 \\
\hline Brüt satıs karı/net satış & 0.11 & 0.07 & 0.16 & 0.19 & 0.15 \\
\hline
\end{tabular}

Tablo 2'de likidite oranlarına bakacak olursak Pegasus Hava Yolları'nın ilk yıllarda bazı oranları düşük olsa da sonraki yıllarda şirketin oranları oldukça yükselmiş ve ortalamalar civarında olup Türk Hava Yolları'ndan da iyi bir performans göstermiştir diyebiliriz. Şirketin borç ödeme gücünün gittikçe yıldan yıla iyi bir seyir izlediğini söyleyebiliriz.

Şirketin mali yapı oranlarını incelersek şirket 2013 yılından itibaren bir toparlanma sürecine girmiş diyebiliriz. Şirketin bazı oranları normalden oldukça yüksek veya düşük çıkmıştır. Bazı yıllarda işletmeye kredi verenlerin işletme sahiplerine göre işletme için daha fazla yatırım yaptığı sonucunu gösterir. İşletme oldukça kredi kullanmış fakat 2013 yılından itibaren oranlarında bir iyileşme olduğu görülmektedir. 
Faaliyet oranlarını ele alırsak şirketin alacaklarını anında tahsil ettiğini görüyoruz bu oran oldukça iyidir. Türkiye şartlarını düşündüğümüzde oran oldukça yüksektir. İşletme borçlarını öderken de herhangi bir sıkıntı ile karşılaşmaz.

Karlılık oranlarını incelersek şirketin karlılık oranlarında da herhangi bir sorun yoktur ve şirketin karlılığı iyidir diyebiliriz. Türk Hava Yolları'ndan da çoğu karlılık oranı yüksek çıkmıştır.

\section{SONUÇ}

Firmaların mali tablolarından yararlanılarak yıldan yıla nasıl bir performans gösterdiğini incelemek oldukça önemlidir. Çünkü firmaların performans sonuçları firmanın kendisi, kamu, yatırım yapanlar ve şirkete yatırım yapmayı düşünen potansiyel yatırımcılar için büyük önem arz etmektedir. Bahsedilen kişi ve kurumlar bu sonuçlara bakarak şirketin gelişimi hakkında varsayımlarda bulunabilirler.

Rasyo analizi en çok kullanılan performans ölçüm yöntemlerinden birisidir. Bu analizde şirketin bilanço ve gelir tablosu kalemleri karşıllklı oranlanarak sonuçlar elde edilir. $\mathrm{Bu}$ oranların sonuçlarına göre firmalar hakkında yorum yapılarak çıkarımlarda bulunulur.

Bu çalışmada BİST'de işlem gören havayolu şirketleri Türk Hava Yolları ile Pegasus Hava Yolları'nın 2010-2015 yılları arası mali tablolarından yararlanılmıştır. Şirketlerin bilanço ve gelir tablosu kalemlerinden yararlanılarak rasyo analizi uygulanmıştır.

Yıllara göre karşılaştırma yapılırsa Türk Hava Yolları'nın 2010 yılında ki cari oranı 1,37 iken diğer yıllarda azaldığ görülmektedir. Özellikle 2012 yılında 0,58 'e kadar düşen bir oran görülmektedir. Pegasus Hava Yolları ise yıllar geçtikçe oranlarında artan bir seyir izlemiştir. Likidite oranı bir şirketin borç ödeme gücünü gösterdiğine göre Türk Hava Yolları'nın oranları düşük yani borçlarını ödeyebilme kapasitesi de düşüktür. Pegasus Hava Yolları'nın ise 2010 yılında cari oranı 0,28 iken 2014 yılına gelindiğinde 1,75'lik bir oran gözlemlenmektedir. Pegasus Hava Yolları'nın borç ödeme gücü yıldan yıla artmıştır.

Faaliyet oranlarında ise; Türk Hava Yolları'nın 2010 yılındaki ortalama tahsil süresi 25,03 gündür ve sonraki yıllarda da azalan bir seyir izlemiş ve 2014 yılında 15,97 güne kadar düşmüştür. Pegasus Hava Yolları'nın ise 2010 yılında 6,91 gün iken 2014 yılında 27,63 güne çıktığı görülmektedir. İki şirkette ortalamalarına göre oldukça iyi sonuçlara sahiptir ve stok konusunda olsun alacaklarını tahsilde olsun herhangi bir güçlükle karşılaşmazlar.

Mali yapı oranları incelenirse; Türk Hava Yolları'nın finansman oranı 2010 yılında 0,65 ve diğer yıllarda da artan bir seyir izleyerek 2014 yılında 0,89 olduğu görülmektedir. Pegasus Hava Yolları'nın finansman oranı 2010 yılında 0,86 iken 2014 yılında 0,67'lere kadar düşmüştür. Finansman oran1 0,50'nin altında olması istenir ve iki şirkette de 0,50'nin üzerindedir. $\mathrm{Bu}$ sonuçlara göre şirketler faaliyetlerini yabancı kaynaklarla karşılamaktadır denilebilir.

Son olarak karlılık oranları incelenirse Türk Hava Yolları'nın kar oranları yıllara göre dalgalanmaktadır. Net karın öz kaynaklara oranı 0,07 iken 2011'de 0,004, 2013'te 0,21 gibi bir oran söz konusudur. 2010 yılında aynı şekilde Pegasus Hava Yolları'nın da 2010'da net karın öz kaynaklara oranı 0,13,2013’te 0,42'dir. Yani iki şirkette karlılık oranlarında yıllara göre dalgalı bir seyir izlemektedir.

Sonuç olarak her iki şirkette finansal yapıdan güçlüdür her ikisine de yatırım yapılabilir. Özellikle alacaklarını tahsil süreleri oldukça iyidir.

Elde edilen sonuçlara göre her iki şirketinde mali yapı oranlarında sorun olduğu fakat diğer oranlarının oldukça iyi olduğu gözlemlenmiştir. İki şirket arasında bir kıyaslama yapacak olursak Pegasus Hava Yolları'nın 2013 yılından itibaren iyi bir seyir izlediğini ve Türk Hava Yolları'ndan iyi olduğunu söyleyebiliriz. Her iki şirkete yatırım yapacak olanların da 
şirketlere yatırım yapılabilir ancak Türk Hava Yolları yerine Pegasus Hava Yolları'na yatırım yapılması tercih edilebilir. 


\section{KAYNAKÇA}

AKGÜÇ Ö. (1994), Finansal Yönetim, 6. Baskı İstanbul

AKTEPE C., ŞAHPA R, 'Türkiye'nin En Büyük Beş Havayolu İşletmesinin Marka Değerini Unsurları Açısından İncelenmesi ve Ankara İli Uygulaması' C.Ü. İktisadi ve İdari Bilimler Dergisi, Cilt 11, Sayı 2, 2010

ALTMAN E., FinancialRatios, Discriminant Analysis And The Prediction of CorporateBankruptcyVOL. XXIII September 1968 No. 4.

BEYAZITLI E., KADERLİ Y., GÜREL E., Kâr Payı Dağıtma Duyurularının Firmaların Hisse Senedi Getirilerine Etkisi: IMKB'YE Kayıtlı, Tas Ve Toprağa Dayalı Sanayide Faaliyet Gösteren Bazı Firmalar Üzerinde Bir Olay Etüdü Çalışması, Muhasebe ve Denetime Bakış Dergisi, Ekim 2008, Y11:8, Sayı:26.

BHUNIA A., MUKHUTI S., and ROY G., India Current Research Journal of Social Sciences 3(3): 269-275, 2011 ISSN: 2041-3246

BERK N., (2002) Finansal Yönetim 6.Bask1 Türkmen Kitabevi İstanbul

BULGURCU B., 'Application of TOPSIS Techniquefor Financial Performance Evaluation of TechnologyFirms in Istanbul Stock Exchange Market.Procedia' - Socialand Behavioral Sciences 62 ( 2012 ) $1033-1040$

ECER F., GÜNAY F. (2014) 'Borsa İstanbul'da İşlem Gören Turizm Şirketlerinin Finansal Performanslarının Gri İlişkisel Analiz Yöntemiyle Ölçülmesi'.Anatolia: Turizm Araştırmaları Dergisi, Cilt 25, Sayı 1, Bahar: 35 - 48, 2014.

EGE İ., TOPALOĞLU E., ÖZYAMANOĞLU (2013) 'Finansal Performans İle Kurumsal Yönetim Notları Arasındaki İlişki: BIST Üzerine Bir Uygulama.' Akademik Araştırmalar ve Çalışmalar Dergisi / Journal of Academic Researchesand Studies Y11 5 - Say1 9 - Kasim 2013 / Volume 5 - Number 9 - November 2013

GÖKIRMAK H. (2014) Türk Havayolları'nın Havacılık Sektöründeki Konumu.

GÜREL E. Kâr Payı Verimi Üzerine Bir Literatür Taraması, Muhasebe ve Vergi Uygulamaları Dergisi, Cilt:4, Sayı:3, 2011.

J.M. SAMUELS R. E. BRAYSHAW F. M. WILKES(2000), Management of Company Finance

KADERLİ Y. (2006) 'IMKB'de İşlem Gören Gıda Sektörü Şirketlerinin Finansal Performanslarının Ölçülmesi ve Özsermaye Karlılığını Etkileyen Faktörlerin Belirlenmesi’ Adnan Menderes Üniversitesi Sosyal Bilimler Enstitüsü İŞ-YL-20060002

KARATAY E., YALÇIN P., ŞAHIN M., KIRTILOĞLU Y. 'Sivil Havac1lık Sektörünün Ulusal ve Uluslar arası Düzeyde İncelenmesi'

KORKMAZ T.,UYGURTÜRK H.,(2012),'Finansal Performansın TOPSIS Çok Kriterli Karar Verme Yöntemi İle Belirlenmesi: Ana Metal Sanayi İşletmeleri Üzerine Bir Uygulama'.Eskişehir Osmangazi Üniversitesi İ̈BF Dergisi, Ekim 2012, 7(2), 95-115

MEYDAN C., YILDIRIM F., S. B.,(2016) Bist100'de İşlem Gören Gıda İşletmelerinin Finansal Performanslarının Gri İlişkisel Analiz Yöntemi Kullanılarak Değerlendirilmesi, Muhasebe ve Finansman Dergisi ,Ocak- 2016.

ÖMÜRBEK V., KINAY B., 'Havayolu Taşımacıllğı Sektöründe Topsis Yöntemiyle Finansal Performans Değerlendirilmesi.' Süleyman Demirel Üniversitesi İktisadi ve İdari Bilimler Fakültesi Dergisi Y.2013, C.18, S.3, s.343-363.

ÖNCÜ M., ÇÖMLEKÇİ İ., ÇOŞKUN E., (2013) 'Havayolu Yolcu Taşıma İşletmelerinin Finansal Etkinliklerinin Ölçümüne İlişkin Bir Araştırma.' Uluslararası Alanya İşletme Fakültesi Dergisi Y11:2013, C:5, S:2, s. 77-86

SAMUELS J. M.,WILKES F. M., BRAYSHAW R.E., (2000) 'Management of Company Finance' 
SUBİAKTO M. 'Financial Performance Analysis of PT.

GarudaIndonesia,Tbk.inComparisonwithOtherRegionalAirlines'.International

Conference on Economicsand Business Management (EBM-2015) July 29-30, 2015

Phuket (Thailand) 